\title{
Getting a head start: turn-of-the-month submission effect for accepted papers in management journals
}

\author{
Liang Meng ${ }^{1,2}$ (D) Haifeng Wang ${ }^{1}\left(\mathbb{D} \cdot\right.$ Pengfei $\operatorname{Han}^{3}$
}

Received: 20 March 2020 / Published online: 25 June 2020

(c) Akadémiai Kiadó, Budapest, Hungary 2020

\begin{abstract}
Intriguing unforced regularities in human behaviors have been reported in varied research domains, including scientometrics. In this study we examine the manuscript submission behavior of researchers, with a focus on its monthly pattern. With a large and reliable dataset which records the submission history of articles published on 10 multidisciplinary journals and 10 management journals over a five-year period (2013-2017), we observe a prominent turn-of-the-month submission effect for accepted papers in management journals but not multidisciplinary journals. This effect gets more pronounced in submissions to top-tier journals and when the first day of a month happens to be a Saturday or Sunday. Sense of ceremony is proposed as a likely explanation of this effect, since the first day of a month is a fundamental temporal landmark which has a 'fresh start effect' on researchers. To conclude, an original and interesting day-of-the-month effect in the academia is reported in this study, which calls for more research attention.
\end{abstract}

Keywords Turn-of-the-month (ToM) $\cdot$ Temporal landmark $\cdot$ Submission date $\cdot$ Manuscript submission $\cdot$ Unforced regularity $\cdot$ Management journal

\section{Introduction}

Ritual and ceremony in their due times kept the world under the sky and the stars in their courses. (Terry Pratchett quotes)

In the past few decades, researchers from varied domains endeavored to probe some interesting unforced regularities in human behaviors (Ausloos et al. 2016). Through observation and analyses of real-world datasets, researchers got to learn about reliable and unbiased behavioral patterns, which may even have an edge over laboratory experimentswhile many potential influencing factors have been well controlled in rigorously-designed

Haifeng Wang

wanghf@shisu.edu.cn

1 School of Business and Management, Shanghai International Studies University, Shanghai, China

2 Wharton Neuroscience Initiative, University of Pennsylvania, Philadelphia, USA

3 School of Accounting, Nanjing University of Finance and Economics, Nanjing, China 
experiments, participants may still try to speculate about the research aims and then act in ways that cater to expectations of the researchers. Till now, many intriguing weekly, monthly, seasonal and/or yearly patterns have been reported. Taking the weekly pattern as an example, days-of-the-week effect have been reported in not only birth dates and morality rates (Herteliu et al. 2015; Pigman et al. 1978), but also financial investments and crimes (Abu Bakar et al. 2014; Cellini and Cuccia 2014).

Publish or perish? We have to embrace it anyway (Pautasso and Schäfer 2010). Indeed, most researchers are increasingly pressured to publish their academic work in a rapid and continual manner so as to sustain and develop their academic careers (researchers including us remain active even in the COVID-19 pandemic). In recent years, some researchers began to examine synchronized behaviors of researchers themselves (Ausloos et al. 2016, 2017; Ausloos, Nedič, et al. 2019a, b; Barnett et al. 2019; Boja et al. 2018; Cabanac and Hartley 2013; Magnone 2013). For instance, Magnone analyzed the relationship between calendar events (e.g., national public holidays, Chinese New Year and Christmas) and scientific article submissions. It was found that researchers were less likely to submit during calendar events (Magnone 2013). A group of researchers explored the fluctuation of submissions within a week and the effect of the submission date on the acceptance/rejection rate of the manuscripts being submitted. Examination of the publication histories of articles published between 2001 and 2012 suggested that a considerable amount of academic activities (submission, revision, and acceptance) were performed by Journal of the American Society for Information Science authors and editors during weekends, and that there was an increasing trend since 2005 (Cabanac and Hartley 2013). Similar findings were observed in manuscripts and peer reviews submitted to The BMJ and BMJ Open between 2012 and 2019 in a recent study (Barnett et al. 2019). Analyses of the submissions to Journal of the Serbian Chemical Society between 2013 and 2014 revealed a Tuesday-Wednesday effect: while most submissions appeared on Wednesday, submissions on Tuesday stood the greatest chance to be accepted. In contrast, acceptance rates were lowest on weekends (Ausloos et al. 2016, 2017). Following this pioneering endeavor, other researchers tested the day-of-the-week submission effect using a much larger and reliable sample incorporating Nature, Cell, PLOS ONE and Physica A. While internal data from these journals could not be acquired, the researchers verified the weekday-weekend effect on accepted papers, as most submissions took place during the weekdays (Boja et al. 2018).

Findings of these pioneering studies should be of broad interest to researchers ourselves, as well as psychologists. For instance, if a manuscript has been well prepared in advance and the authors deliberately choose the submission date, then this information can tell a lot about their internal mental processes. While causal effects were not tested, and we should be really cautious when interpreting these results, at least these results suggest that there are indeed synchronized submission-related behaviors. Given that these results are illuminating, existing analyses were conducted on a relatively narrow time scale (e.g., the weekly pattern) (Ausloos et al. 2016, 2017; Boja et al. 2018). Extending this line of studies, we would like to examine whether there are any day-of-the-month effects in academic submissions. Considering that reputation of the journals may have a considerable impact on the submission decision, dates of submissions to both top-tier journals and middle-grade journals are retrieved and analyzed. As we conjecture that researchers from different research domains may exhibit varied patterns when choosing their submission dates (e.g., some researchers may pay little attention to the submission date and would submit their manuscripts as soon as they are ready, while researchers in other domains may tend to carefully choose the submission date), we retrieve and analyze submissions to both multidisciplinary 
sciences journals and operations research \& management science journals that are indexed by Science Citation Index Expanded (SCIE) (Zhu and Liu 2020).

\section{Materials and methods}

\section{Data collection process}

Our analyses are based on public data retrieved from the official websites of selected academic journals. While the full texts of academic papers may not be publicly available, everyone has access to the title, abstract and author information. Besides, many journals provide a brief history of the papers' peer review process on their websites, which makes it possible for us to conduct this study. Consistent with pioneering endeavors (Boja et al. 2018; Cabanac and Hartley 2013), the publication metadata we use in our analyses (e.g., submission date, article type) are automatically retrieved from the selected journals' official websites using a tailor-made web scraper. As management researchers ourselves, we pay attention to two categories of journals included in the SCIE database. According to descriptions in Journal Citation Reports (JCR), the category of multidisciplinary sciences (multidisciplinary journals for short) covers journals of a very broad or general character in the sciences. Within the same journal, one may find papers of several major scientific disciplines, from biology, chemistry, mathematics to physics. In comparison, operations research \& management science (management journals for short) is a more narrowly defined category, which is dedicated to the publication of papers contributing to managerial decision-making.

As there are 64 and 84 journals in multidisciplinary and management categories respectively by the year 2017 , these journals go through a screening stage before they are included in our analyses. The screening criteria are as follows: (1) The submission dates should be publicly accessible on the official websites; (2) By the year 2017, the included journals should have a publication history of more than 5 years; (3) The selected journals should publish no less than 4 issues each year; (4) The selected journals should take publishing academic papers as the main objective (those which mainly publish news reports are excluded). 10 journals from the multidisciplinary sciences category meet all these criteria, all of which are included in our analyses. 47 journals from the operations research \& management science category meet these requirements. To make the number of journals compatible between the two categories, a random drawing procedure is implemented for management journals. The 10 multidisciplinary sciences journals included in our dataset are Nature, Science, Proceedings of the National Academy of Sciences of the United States of America (PNAS), Journal of the Royal Society Interface, The Science of Nature, Proceedings of the Royal Society A-Mathematical Physical and Engineering Sciences, Journal of the Royal Society of New Zealand, Proceedings of the National Academy of Sciences India Section A-Physical Sciences, Interdisciplinary Science Reviews, and National Academy Science Letters-India. The 10 management journals included in our dataset are Operations Research, Energy Policy, Technovation, Production Planning \& Control, 4OR-A Quarterly Journal of Operations Research, Insurance Mathematics \& Economics, Quality \& Quantity, Studies in History and Philosophy of Science, Interfaces, and INFOR: Information Systems and Operational Research. It is worth noting that not all the papers that appear in these journals between 2013 and 2017 go into our analyses. As it is unlikely that some papers would go through a peer review process (e.g., editorials, corrigenda, etc.), 
these data are removed from the final dataset. Based on the screening methods above, we get a database of 25,947 articles published on 10 multidisciplinary journals and another 5150 articles published on 10 management journals over a five-year period (2013-2017). As many journals in our dataset do not provide information about the submission date of revisions, and we cannot obtain data about the journals' acceptance and rejection decisions in the peer review process, our analyses are confined to the first submission of accepted manuscripts only (Boja et al. 2018).

\section{Measurements}

Besides conducting descriptive analyses of the monthly submission patterns to both multidisciplinary and management journals, regression analyses are carried out to test whether a journal's impact factor has an influence on the submission date of an article.

\section{Dependent variable}

As the first day of a month is commonly accepted as a fundamental temporal landmark, which has been suggested to produce a 'fresh start effect' for researchers (Dai et al. 2014; Dai and Li 2019), submission on the first day of a month is defined as the dependent variable. We adopt a dummy variable to measure whether a manuscript was submitted to the journal on the first day of a month $(1=$ yes, $0=$ no $)$.

\section{Independent variable}

Impact factor of the journal (impact factor for short). We adopt the journal's 5-year impact factor to reflect its academic reputation. Given that JCR are updated by the end of each June, we adopt the journal's 5-year impact factor of the year before last when analyzing the articles submitted between January and June of a year. The journal's 5-year impact factor of the previous year is adopted when analyzing the articles submitted between July and December of a year. For instance, if a manuscript was submitted to a journal in October 2015, then the 5-year impact factor of 2014 would be adopted, since this was the most updated impact factor to the researchers upon manuscript submission. In a similar manner, if a manuscript was submitted to a journal in May 2017, then the 5-year impact factor of 2015 would be adopted.

\section{Moderating variables}

Submission at weekends. We adopt this dummy variable to measure whether the submission date fell on weekends $(1=$ yes, $0=$ no). To be more specific, we adopt the dummy variable submission on Saturday to measure whether a manuscript was submitted to the journal on a Saturday $(1=$ yes, $0=$ no). The dummy variable submission on Sunday is adopted to measure whether a manuscript was submitted to the journal on a Sunday $(1=$ yes, $0=$ no). It is worth pointing out that, while we realize that some countries have special weekends, which include Friday and Saturday instead of Saturday and Sunday, in this study we adopt the more prevalent definition of weekends, as the submitting authors' origin country information is not available in our dataset. Future researchers can take special weekends into accounts, as was did in some pioneering studies (Boja et al. 2018; Campos-Arceiz et al. 2013). 


\section{Results}

\section{Descriptive analyses and Chi-square tests}

Table 1 illustrates the distribution of the submission date of articles published on the selected management and multidisciplinary journals over the 5-year period (2013-2017). Suppose each month has 31 days. If manuscript submissions were evenly distributed among each day of a month, then 166.13 published articles $($ Std. =74.62) should be submitted to management journals on each day of a month (which accounts for $3.23 \%$ of the articles published on these journals monthly; Std.=1.45\%), while $837.00($ Std. $=71.54)$ should be submitted to multidisciplinary journals on each day of a month $(3.23 \%$, Std. $=0.28 \%)$.

Table 1 The comparison between daily submissions to management journals and multidisciplinary journals

\begin{tabular}{|c|c|c|c|c|c|}
\hline \multicolumn{3}{|c|}{ Management $(N=5150)$} & \multicolumn{3}{|c|}{ Multidisciplinary $(N=25,947)$} \\
\hline Date & Amount & Percentage (\%) & Date & Amount & Percentage $(\%)$ \\
\hline $1 \mathrm{st}$ & 561 & 10.89 & $1 \mathrm{st}$ & 816 & 3.14 \\
\hline 2 nd & 163 & 3.17 & 2 nd & 842 & 3.25 \\
\hline $3 r d$ & 163 & 3.17 & $3 \mathrm{rd}$ & 909 & 3.50 \\
\hline 4 th & 172 & 3.34 & 4 th & 861 & 3.32 \\
\hline 5 th & 164 & 3.18 & 5 th & 829 & 3.19 \\
\hline 6 th & 145 & 2.82 & 6th & 865 & 3.33 \\
\hline 7 th & 150 & 2.91 & 7 th & 850 & 3.28 \\
\hline 8 th & 150 & 2.91 & 8th & 876 & 3.38 \\
\hline 9 th & 153 & 2.97 & 9th & 854 & 3.29 \\
\hline 10th & 155 & 3.01 & 10 th & 909 & 3.50 \\
\hline 11 th & 169 & 3.28 & 11 th & 837 & 3.23 \\
\hline 12 th & 152 & 2.95 & 12 th & 881 & 3.40 \\
\hline 13th & 156 & 3.03 & 13th & 858 & 3.31 \\
\hline 14 th & 145 & 2.82 & 14 th & 859 & 3.31 \\
\hline 15 th & 159 & 3.09 & 15 th & 879 & 3.39 \\
\hline 16th & 165 & 3.20 & 16th & 851 & 3.28 \\
\hline 17 th & 155 & 3.01 & 17 th & 882 & 3.40 \\
\hline 18th & 162 & 3.15 & 18th & 853 & 3.29 \\
\hline 19 th & 163 & 3.17 & 19th & 840 & 3.24 \\
\hline 20 th & 149 & 2.89 & 20 th & 872 & 3.36 \\
\hline $21 \mathrm{st}$ & 142 & 2.76 & $21 \mathrm{st}$ & 842 & 3.25 \\
\hline 22nd & 151 & 2.93 & $22 \mathrm{nd}$ & 877 & 3.38 \\
\hline $23 \mathrm{rd}$ & 162 & 3.15 & $23 \mathrm{rd}$ & 878 & 3.38 \\
\hline 24 th & 144 & 2.80 & 24th & 782 & 3.01 \\
\hline 25 th & 140 & 2.72 & 25 th & 843 & 3.25 \\
\hline 26 th & 144 & 2.80 & 26th & 793 & 3.06 \\
\hline 27 th & 156 & 3.03 & 27 th & 823 & 3.17 \\
\hline 28th & 156 & 3.03 & 28th & 814 & 3.14 \\
\hline 29th & 160 & 3.11 & 29th & 777 & 2.99 \\
\hline 30th & 153 & 2.97 & 30th & 800 & 3.08 \\
\hline $31 \mathrm{st}$ & 91 & 1.77 & $31 \mathrm{st}$ & 495 & 1.91 \\
\hline
\end{tabular}


Here, we consider that the probability of articles submitted to journals on the first day of a month should be $3.23 \%$ (computed as $1 / 31$ ) if submission dates were completely random within a month, and we adopt $3.29 \%$ (computed as $12 / 365$ ) to replace $3.23 \%$ during our robustness checks. Intriguingly, compared with other dates, the amount of submissions to management journals dramatically increases on the first day of a month. As indicated by results in Table 1, 561 published articles $(10.89 \%)$ were submitted to management journals and 816 published articles $(3.14 \%)$ were submitted to multidisciplinary journals on the first day of a month. Six Sigma is a disciplined, data-driven method for the detection of unforced regularities and/or outliers (Borowski et al. 2015). It is worth noting that, 561 is much bigger than the average submission amount added to triple standard deviation of the submission per day $(166.13+3 * 74.62)$. Similarly, $10.89 \%$ is much bigger than the average percentage added to triple standard deviation of it $(3.23 \%+3 * 1.45 \%)$. Given that the 31 st day appears only seven times a year and may bias the results, we multiply submissions on that day with 12/7. Still, an explosion of submission is observed only on the first day of a month and only in management journals. Thus, according to the Six Sigma principle, we observe a turn-of-the-month (ToM) effect in manuscript submissions to management journals. In line with a previous study, we adopt Chi-square tests to examine the distribution of the submission date against uniformity (Boja et al. 2018). As the 31st day is unevenly distributed among the 12 months, which may bias the results, we remove all submissions on the 31 st day of a month. For management journals, the Chi-square value is statistically significant (Chi-square $=956.01, p<0.001, N=5,059)$, which further supports the ToM effect observed in management journals. For multidisciplinary journals, the Chi-square value is not significant (Chi-square $=38.51, p>0.1, N=25,452$ ), which further suggests that there are not significant deviations from uniformity in submissions to multidisciplinary journals.

To further explore the ToM effect, we examine whether journals' influencing factors would impact researchers' submission behaviors. According to the ranking of influencing factors, the selected journals are classified into top-tier journals and middle-grade journals. Because each category includes 10 journals, the top five journals which have greater impact factors within each category are defined as top-tier journals, while the rest journals are defined as middle-grade journals. Table 2 illustrates the distribution of the submission date of articles published on top-tier and middle-grade management journals over the 5-year period (2013-2017). 4,216 published articles (136.00 per day per month, Std. $=69.01$; percentage $=3.23 \%$, Std. $=1.64 \%$ ) were submitted to top-tier management journals, while 934 published articles (30.13 per day per month, Std. $=8.18$; percentage $=3.23 \%$, Std. $=0.88 \%$ ) were submitted to middle-grade management journals. 501 published articles were submitted to top-tier management journals on the first day of a month, which is much bigger than the average submission amount added to triple standard deviation of the submission per day $(136.00+3 * 69.01)$. Similarly, $11.88 \%$ is much bigger than the average percentage added to triple standard deviation of it $(3.23 \%+3 * 1.64 \%) .60$ published articles were submitted to middle-grade management journals on the first day of a month, which is greater than the average submission amount added to triple standard deviation of the submission per day $(30.13+3 * 8.18)$. Similarly, $6.42 \%$ is greater than the average percentage added to triple standard deviation of it $(3.23 \%+3 * 0.88 \%)$. Furthermore, for top-tier management journals, the Chi-square value is statistically significant (Chi-square $=1003.66, p<0.001$, $N=4,144$ ), which further supports the ToM effect observed in top-tier management journals. For middle-grade management journals, the Chi-square value is significant as well (Chi-square $=61.56, p<0.001, N=915$ ), which further supports the ToM effect observed in middle-grade management journals. Thus, the ToM effect is observed in submissions to both top-tier and middle-grade management journals. 
Table 2 The comparison between daily submissions to top-tier and middle-grade management journals

\begin{tabular}{|c|c|c|c|c|c|}
\hline \multicolumn{3}{|c|}{ Top-tier Management $(N=4216)$} & \multicolumn{3}{|c|}{$\begin{array}{l}\text { Middle-grade Management } \\
(N=934)\end{array}$} \\
\hline Date & Amount & Percentage $(\%)$ & Date & Amount & Percentage $(\%)$ \\
\hline $1 \mathrm{st}$ & 501 & 11.88 & $1 \mathrm{st}$ & 60 & 6.42 \\
\hline 2nd & 139 & 3.30 & $2 \mathrm{nd}$ & 24 & 2.57 \\
\hline $3 r d$ & 130 & 3.08 & 3 rd & 33 & 3.53 \\
\hline 4 th & 133 & 3.15 & 4th & 39 & 4.18 \\
\hline 5 th & 130 & 3.08 & 5 th & 34 & 3.64 \\
\hline 6 th & 123 & 2.92 & 6 th & 22 & 2.36 \\
\hline 7 th & 124 & 2.94 & 7 th & 26 & 2.78 \\
\hline 8 th & 124 & 2.94 & 8th & 26 & 2.78 \\
\hline 9th & 114 & 2.70 & 9 th & 39 & 4.18 \\
\hline 10th & 127 & 3.01 & 10th & 28 & 3.00 \\
\hline 11th & 143 & 3.39 & 11th & 26 & 2.78 \\
\hline 12 th & 115 & 2.73 & 12 th & 37 & 3.96 \\
\hline 13th & 137 & 3.25 & 13th & 19 & 2.03 \\
\hline 14 th & 108 & 2.56 & 14th & 37 & 3.96 \\
\hline 15 th & 135 & 3.20 & 15 th & 24 & 2.57 \\
\hline 16 th & 135 & 3.20 & 16 th & 30 & 3.21 \\
\hline 17 th & 124 & 2.94 & 17 th & 31 & 3.32 \\
\hline 18th & 133 & 3.15 & 18th & 29 & 3.10 \\
\hline 19th & 134 & 3.18 & 19th & 29 & 3.10 \\
\hline 20th & 118 & 2.80 & 20th & 31 & 3.32 \\
\hline $21 \mathrm{st}$ & 119 & 2.82 & $21 \mathrm{st}$ & 23 & 2.46 \\
\hline 22nd & 108 & 2.56 & 22nd & 43 & 4.60 \\
\hline $23 \mathrm{rd}$ & 139 & 3.30 & $23 \mathrm{rd}$ & 23 & 2.46 \\
\hline 24th & 119 & 2.82 & 24th & 25 & 2.68 \\
\hline 25 th & 118 & 2.80 & 25 th & 22 & 2.36 \\
\hline 26 th & 116 & 2.75 & 26 th & 28 & 3.00 \\
\hline 27 th & 122 & 2.89 & 27 th & 34 & 3.64 \\
\hline 28th & 123 & 2.92 & 28 th & 33 & 3.53 \\
\hline 29th & 131 & 3.11 & 29th & 29 & 3.10 \\
\hline 30th & 122 & 2.89 & 30th & 31 & 3.32 \\
\hline $31 \mathrm{st}$ & 72 & 1.71 & $31 \mathrm{st}$ & 19 & 2.03 \\
\hline
\end{tabular}

Compared with the average submission amount on each day of a month, for top-tier management journals the deviation of the submission on the first day of the month is around 5.29 times the standard deviation (501 is approximately $136.00+5.29 * 69.01)$, while it is about 3.65 times the standard deviation (60 is approximately $30.13+3.65 * 8.18$ ) for middle-grade management journals. Likewise, the percentage of submissions shows the same pattern. The deviation is 5.29 times the standard deviation (11.88\% is approximately $3.23 \%+5.29 * 1.64 \%$ ) for top-tier management journals and is 3.65 times the standard deviation $(6.42 \%$ is approximately $3.23 \%+3.65 * 0.88 \%)$ for middle-grade management journals. The greater deviation illustrates a stronger ToM effect. Thus, we observe a more pronounced ToM effect in submissions to top-tier management journals compared with middle-grade ones. 
To further examine the ToM effect, we explore whether this effect would still be observed when the first day of a month happened to fall on weekends (i.e., Saturday and Sunday). Table 3 illustrates the distribution of weekend submissions of articles published on both management and multidisciplinary journals over the 5-year period (2013-2017). 867 and 2805 published articles were submitted to management and multidisciplinary journals at weekends, respectively. As each day of a month stands an equal probability to fall on weekends, on average 27.97 published articles $(\mathrm{Std} .=23.05)$ should be submitted to management journals per day per month $(3.23 \%$, Std. $=2.66 \%)$, while $90.48($ Std. $=13.25)$ should be submitted to multidisciplinary journals per day per month $(3.23 \%$, Std. $=0.47 \%)$. Similar with previous analyses, we do not observe an evident ToM effect in weekend submissions to multidisciplinary journals. However, the ToM effect still exists in submissions to management journals when only weekend submissions are considered. As shown in

Table 3 The comparison between weekend submissions to management journals and multidisciplinary journals

\begin{tabular}{|c|c|c|c|c|c|}
\hline \multicolumn{3}{|c|}{ Management $(N=867)$} & \multicolumn{3}{|c|}{ Multidisciplinary $(N=2,805)$} \\
\hline Date & Amount & Percentage (\%) & Date & Amount & Percentage $(\%)$ \\
\hline $1 \mathrm{st}$ & 149 & 17.19 & $1 \mathrm{st}$ & 109 & 3.89 \\
\hline 2 nd & 25 & 2.88 & 2 nd & 105 & 3.74 \\
\hline $3 \mathrm{rd}$ & 28 & 3.23 & $3 \mathrm{rd}$ & 81 & 2.89 \\
\hline 4 th & 25 & 2.88 & 4 th & 92 & 3.28 \\
\hline 5 th & 27 & 3.11 & 5 th & 80 & 2.85 \\
\hline 6 th & 27 & 3.11 & 6 th & 114 & 4.06 \\
\hline 7 th & 22 & 2.54 & 7 th & 99 & 3.53 \\
\hline 8 th & 27 & 3.11 & 8th & 94 & 3.35 \\
\hline 9th & 28 & 3.23 & 9 th & 99 & 3.53 \\
\hline 10 th & 25 & 2.88 & 10 th & 79 & 2.82 \\
\hline 11 th & 19 & 2.19 & 11 th & 80 & 2.85 \\
\hline 12 th & 33 & 3.81 & 12 th & 110 & 3.92 \\
\hline 13th & 18 & 2.08 & 13th & 91 & 3.24 \\
\hline 14 th & 23 & 2.65 & 14 th & 93 & 3.32 \\
\hline 15 th & 37 & 4.27 & 15 th & 104 & 3.71 \\
\hline 16th & 26 & 3.00 & 16 th & 89 & 3.17 \\
\hline 17 th & 24 & 2.77 & 17 th & 90 & 3.21 \\
\hline 18th & 26 & 3.00 & 18 th & 88 & 3.14 \\
\hline 19 th & 20 & 2.31 & 19th & 96 & 3.42 \\
\hline 20th & 21 & 2.42 & 20 th & 92 & 3.28 \\
\hline $21 \mathrm{st}$ & 24 & 2.77 & $21 \mathrm{st}$ & 97 & 3.46 \\
\hline 22nd & 26 & 3.00 & $22 \mathrm{nd}$ & 96 & 3.42 \\
\hline $23 \mathrm{rd}$ & 20 & 2.31 & $23 \mathrm{rd}$ & 99 & 3.53 \\
\hline 24 th & 19 & 2.19 & 24 th & 72 & 2.57 \\
\hline 25 th & 13 & 1.50 & 25 th & 72 & 2.57 \\
\hline 26th & 17 & 1.96 & $26 \mathrm{th}$ & 78 & 2.78 \\
\hline 27 th & 20 & 2.31 & 27 th & 90 & 3.21 \\
\hline 28th & 33 & 3.81 & 28th & 93 & 3.32 \\
\hline 29th & 25 & 2.88 & 29 th & 83 & 2.96 \\
\hline 30th & 25 & 2.88 & 30 th & 93 & 3.32 \\
\hline $31 \mathrm{st}$ & 15 & 1.73 & $31 \mathrm{st}$ & 47 & 1.68 \\
\hline
\end{tabular}


Table 3, 149 published articles (17.19\%) were submitted to management journals on the first day of a month when it happened to fall on weekends, which is much bigger than the average submission amount added to triple standard deviation of the submission per day per month $(27.97+3 * 23.05)$. Similarly, $17.19 \%$ is much bigger than the average percentage added to triple standard deviation of it $(3.23 \%+3 * 2.66 \%)$. As a larger percentage of submissions accumulate on the first day of a month when only weekend submissions are analyzed (17.19\%) than when both weekday and weekend submissions are analyzed (10.89\%), we conclude that the ToM effect gets more pronounced when the first day of a month happened to be a Saturday or Sunday. Furthermore, for weekend submissions to management journals, the Chi-square value is statistically significant (Chi-square $=555.25, p<0.001$, $N=852$ ), which supports the ToM effect in weekend submissions to management journals. However, the Chi-square value is not significant (Chi-square $=36.00, p>0.1, N=2758$ ) in weekend submissions to multidisciplinary journals, which further suggests that there are not significant deviations from uniformity in weekend submissions to these journals.

\section{Robustness checks}

The following robustness checks are implemented to further verify our results. First, we examine submissions to top-tier and middle-grade management journals at weekends. Table 4 displays the distribution of weekend submissions of articles published on top-tier and middle-grade management journals over the 5-year period (2013-2017). 709 published articles $(22.87$ per day, Std. $=21.12$; percentage $=3.23 \%$, Std. $=2.98 \%)$ were submitted to top-tier management journals at weekends, while 158 published articles (5.10 per day, Std. $=2.98$; percentage $=3.23 \%$, Std $=1.89 \%$ ) were submitted to middle-grade management journals at weekends. When the first day of a month happened to be a Saturday or Sunday, both the absolute quantity and the percentage exceed triple standard deviations of weekend submissions per day per month (top-tier management journals: $134>22.87+3 * 22.12$, $18.90 \%>3.23 \%+3 * 2.98 \%$; middle-grade management journals: $15>5.10+3 * 2.98$, $9.49 \%>3.23 \%+3 * 1.89 \%$ ). Besides, for weekend submissions to top-tier management journals, the Chi-square value is statistically significant (Chi-square $=563.07, p<0.001$, $N=701$ ), which further supports the ToM effect observed in weekend submissions to toptier management journals. For weekend submissions to middle-grade management journals, the Chi-square value is also significant (Chi-square $=45.47, p<0.05, N=151$ ), which further supports the ToM effect observed in weekend submissions to middle-grade management journals. Thus, the ToM effect is observed in submissions to both top-tier and middle-grade management journals at weekends. However, the fact that the deviation is around 5.26 times the standard deviation for top tier management journals while is only about 3.32 times the standard deviation for middle-grade management journals suggests a more pronounced ToM effect in weekend submissions to top-tier management journals compared with weekend submissions to middle-grade ones.

Second, we further divide weekends into Saturday and Sunday to check the robustness of the ToM effect at weekends. Table 5 displays the distribution of Saturday versus Sunday submissions of articles published on management journals over the 5-year period (2013-2017). 484 published articles (15.61 per day, Std.=12.46; percentage $=3.23 \%$, Std. $=2.57 \%$ ) were submitted to management journals on Saturdays, while 383 published articles (12.35 per day, Std. $=11.05$; percentage $=3.23 \%$, Std $=2.88 \%$ ) were submitted to management journals on Sundays. When the first day of a month happened to be a Saturday or Sunday, both the absolute quantity and the percentage 
Table 4 The comparison between weekend submissions to top-tier and middle-grade management journals

\begin{tabular}{|c|c|c|c|c|c|}
\hline \multicolumn{3}{|c|}{ Top-tier Management $(N=709)$} & \multicolumn{3}{|c|}{$\begin{array}{l}\text { Middle-grade Management } \\
(N=158)\end{array}$} \\
\hline Date & Amount & Percentage (\%) & Date & Amount & Percentage (\%) \\
\hline $1 \mathrm{st}$ & 134 & 18.90 & $1 \mathrm{st}$ & 15 & 9.49 \\
\hline $2 \mathrm{nd}$ & 22 & 3.10 & 2 nd & 3 & 1.90 \\
\hline $3 \mathrm{rd}$ & 23 & 3.24 & $3 r d$ & 5 & 3.16 \\
\hline 4 th & 23 & 3.24 & 4 th & 2 & 1.27 \\
\hline 5 th & 23 & 3.24 & 5 th & 4 & 2.53 \\
\hline 6 th & 24 & 3.39 & 6 th & 3 & 1.90 \\
\hline 7 th & 22 & 3.10 & 7 th & 0 & 0.00 \\
\hline 8 th & 21 & 2.96 & 8 th & 6 & 3.80 \\
\hline 9th & 20 & 2.82 & 9th & 8 & 5.06 \\
\hline 10 th & 20 & 2.82 & 10th & 5 & 3.16 \\
\hline 11th & 14 & 1.97 & 11th & 5 & 3.16 \\
\hline 12 th & 24 & 3.39 & 12 th & 9 & 5.70 \\
\hline 13th & 14 & 1.97 & 13th & 4 & 2.53 \\
\hline 14 th & 18 & 2.54 & 14 th & 5 & 3.16 \\
\hline 15 th & 29 & 4.09 & 15 th & 8 & 5.06 \\
\hline 16 th & 21 & 2.96 & 16 th & 5 & 3.16 \\
\hline 17 th & 18 & 2.54 & 17 th & 6 & 3.80 \\
\hline 18th & 22 & 3.10 & 18th & 4 & 2.53 \\
\hline 19th & 15 & 2.12 & 19th & 5 & 3.16 \\
\hline 20th & 20 & 2.82 & 20th & 1 & 0.63 \\
\hline $21 \mathrm{st}$ & 19 & 2.68 & $21 \mathrm{st}$ & 5 & 3.16 \\
\hline 22nd & 18 & 2.54 & $22 \mathrm{nd}$ & 8 & 5.06 \\
\hline $23 r d$ & 16 & 2.26 & $23 \mathrm{rd}$ & 4 & 2.53 \\
\hline 24th & 17 & 2.40 & 24th & 2 & 1.27 \\
\hline 25 th & 11 & 1.55 & 25 th & 2 & 1.27 \\
\hline 26th & 13 & 1.83 & 26 th & 4 & 2.53 \\
\hline 27 th & 13 & 1.83 & 27 th & 7 & 4.43 \\
\hline 28th & 24 & 3.39 & 28th & 9 & 5.70 \\
\hline 29th & 24 & 3.39 & 29th & 1 & 0.63 \\
\hline 30th & 19 & 2.68 & 30th & 6 & 3.80 \\
\hline $31 \mathrm{st}$ & 8 & 1.13 & $31 \mathrm{st}$ & 7 & 4.43 \\
\hline
\end{tabular}

far exceed three standard deviations (Saturday submissions: $80>15.61+3 * 12.46$, $16.53 \%>3.23 \%+3 * 2.57 \% ; \quad$ Sunday submissions: $\quad 69>12.35+3 * 11.05$, $18.02 \%>3.23 \%+3 * 2.88 \%$ ). For Saturday submissions to management journals, the Chi-square value is statistically significant (Chi-square $=289.76, p<0.001, N=476$ ), which further supports the ToM effect observed in Saturday submissions to management journals. For Sunday submissions to management journals, the Chi-square value is also statistically significant (Chi-square $=289.75, p<0.001, N=376$ ), which further supports the ToM effect observed in Sunday submissions to management journals. Thus, according to descriptive analyses and Chi-square tests, pronounced ToM effects are observed on both Saturday and Sunday submissions to management journals. 
Table 5 The comparison between Saturday and Sunday submissions to management journals

\begin{tabular}{|c|c|c|c|c|c|}
\hline \multicolumn{3}{|c|}{ Saturday $(N=484)$} & \multicolumn{3}{|c|}{ Sunday $(N=383)$} \\
\hline Date & Amount & Percentage (\%) & Date & Amount & Percentage (\%) \\
\hline 1 st & 80 & 16.53 & $1 \mathrm{st}$ & 69 & 18.02 \\
\hline 2nd & 15 & 3.10 & 2nd & 10 & 2.61 \\
\hline $3 r d$ & 15 & 3.10 & $3 \mathrm{rd}$ & 13 & 3.39 \\
\hline 4th & 20 & 4.13 & 4th & 5 & 1.31 \\
\hline 5 th & 15 & 3.10 & 5 th & 12 & 3.13 \\
\hline 6th & 15 & 3.10 & 6th & 12 & 3.13 \\
\hline 7th & 17 & 3.51 & 7th & 5 & 1.31 \\
\hline 8th & 15 & 3.10 & 8th & 12 & 3.13 \\
\hline 9th & 15 & 3.10 & 9th & 13 & 3.39 \\
\hline 10th & 15 & 3.10 & 10th & 10 & 2.61 \\
\hline 11th & 11 & 2.27 & 11th & 8 & 2.09 \\
\hline 12th & 21 & 4.34 & 12th & 12 & 3.13 \\
\hline 13th & 11 & 2.27 & 13th & 7 & 1.83 \\
\hline 14th & 12 & 2.48 & 14th & 11 & 2.87 \\
\hline 15th & 16 & 3.31 & 15 th & 21 & 5.48 \\
\hline 16th & 16 & 3.31 & 16th & 10 & 2.61 \\
\hline 17th & 11 & 2.27 & 17th & 13 & 3.39 \\
\hline 18th & 17 & 3.51 & 18th & 9 & 2.35 \\
\hline 19th & 7 & 1.45 & 19th & 13 & 3.39 \\
\hline 20th & 10 & 2.07 & 20th & 11 & 2.87 \\
\hline $21 \mathrm{st}$ & 10 & 2.07 & $21 \mathrm{st}$ & 14 & 3.66 \\
\hline 22nd & 13 & 2.69 & 22nd & 13 & 3.39 \\
\hline $23 \mathrm{rd}$ & 12 & 2.48 & $23 r d$ & 8 & 2.09 \\
\hline 24th & 11 & 2.27 & 24th & 8 & 2.09 \\
\hline 25th & 9 & 1.86 & 25 th & 4 & 1.04 \\
\hline 26th & 10 & 2.07 & 26th & 7 & 1.83 \\
\hline 27 th & 12 & 2.48 & 27 th & 8 & 2.09 \\
\hline 28th & 21 & 4.34 & 28th & 12 & 3.13 \\
\hline 29th & 12 & 2.48 & 29th & 13 & 3.39 \\
\hline 30th & 12 & 2.48 & 30th & 13 & 3.39 \\
\hline $31 \mathrm{st}$ & 8 & 1.65 & $31 \mathrm{st}$ & 7 & 1.83 \\
\hline
\end{tabular}

Third, as we notice that 16,418 articles were published on PNAS, accounting for $63.3 \%$ of all the articles published on the 10 multidisciplinary journals during 2013-2017, we eliminate articles published on PNAS from the original database and obtain a new database of 9529 articles published on multidisciplinary journals and another 5150 articles published on management journals between 2013 and 2017. Table 6 illustrates the distribution of the submission date of published articles in this new database. On average, 307.39 published articles $($ Std. $=32.75)$ were submitted to multidisciplinary journals per day per month (percentage $=3.23 \%$, Std. $=0.34 \%$ ). The Chi-square value is non-significant (Chi-square $=42.43, p>0.05, N=9,357$ ), suggesting no significant deviations from uniformity among these submissions. Thus, the ToM effect is not observed in submissions to the rest multidisciplinary journals excluding PNAS. 
Table 6 The comparison between daily submissions to management journals and multidisciplinary journals excluding PNAS

\begin{tabular}{|c|c|c|c|c|c|}
\hline \multicolumn{3}{|c|}{ Management $(N=5150)$} & \multicolumn{3}{|c|}{$\begin{array}{l}\text { Multidisciplinary w/o PNAS } \\
(N=9529)\end{array}$} \\
\hline Date & Amount & Percentage $(\%)$ & Date & Amount & Percentage $(\%)$ \\
\hline $1 \mathrm{st}$ & 561 & 10.89 & 1 st & 268 & 2.81 \\
\hline 2nd & 163 & 3.17 & $2 \mathrm{nd}$ & 309 & 3.24 \\
\hline $3 \mathrm{rd}$ & 163 & 3.17 & $3 r d$ & 340 & 3.57 \\
\hline 4 th & 172 & 3.34 & 4 th & 325 & 3.41 \\
\hline 5 th & 164 & 3.18 & 5 th & 314 & 3.30 \\
\hline 6 th & 145 & 2.82 & 6th & 311 & 3.26 \\
\hline 7 th & 150 & 2.91 & 7 th & 329 & 3.45 \\
\hline 8th & 150 & 2.91 & 8th & 329 & 3.45 \\
\hline 9th & 153 & 2.97 & 9 th & 313 & 3.28 \\
\hline 10th & 155 & 3.01 & 10th & 356 & 3.74 \\
\hline 11 th & 169 & 3.28 & 11th & 328 & 3.44 \\
\hline 12 th & 152 & 2.95 & 12 th & 305 & 3.20 \\
\hline 13th & 156 & 3.03 & 13 th & 307 & 3.22 \\
\hline 14 th & 145 & 2.82 & 14 th & 310 & 3.25 \\
\hline 15 th & 159 & 3.09 & 15 th & 337 & 3.54 \\
\hline 16th & 165 & 3.20 & 16th & 309 & 3.24 \\
\hline 17 th & 155 & 3.01 & 17 th & 351 & 3.68 \\
\hline 18th & 162 & 3.15 & 18th & 277 & 2.91 \\
\hline 19th & 163 & 3.17 & 19th & 303 & 3.18 \\
\hline 20th & 149 & 2.89 & 20th & 325 & 3.41 \\
\hline $21 \mathrm{st}$ & 142 & 2.76 & $21 \mathrm{st}$ & 287 & 3.01 \\
\hline $22 \mathrm{nd}$ & 151 & 2.93 & $22 \mathrm{nd}$ & 301 & 3.16 \\
\hline 23rd & 162 & 3.15 & $23 \mathrm{rd}$ & 304 & 3.19 \\
\hline 24 th & 144 & 2.80 & 24 th & 278 & 2.92 \\
\hline 25 th & 140 & 2.72 & 25 th & 324 & 3.40 \\
\hline 26th & 144 & 2.80 & 26th & 288 & 3.02 \\
\hline 27 th & 156 & 3.03 & 27 th & 330 & 3.46 \\
\hline 28th & 156 & 3.03 & 28th & 296 & 3.11 \\
\hline 29th & 160 & 3.11 & 29th & 288 & 3.02 \\
\hline 30th & 153 & 2.97 & 30th & 315 & 3.31 \\
\hline $31 \mathrm{st}$ & 91 & 1.77 & $31 \mathrm{st}$ & 172 & 1.81 \\
\hline
\end{tabular}

Finally, in the above analyses, we consider that the probability of articles submitted to journals on the first day of a month should be $3.23 \%$ (computed as 1/31) if submission dates were completely random. We adopt $3.29 \%$ (computed as $12 / 365$ ) to replace $3.23 \%$ during robustness checks. All the result patterns remain consistent.

\section{Logistic regression analyses}

Logistic regressions are conducted to further examine the ToM effect, and the results are shown in Table 7 . The logistic regression equations in this study are as follows. 


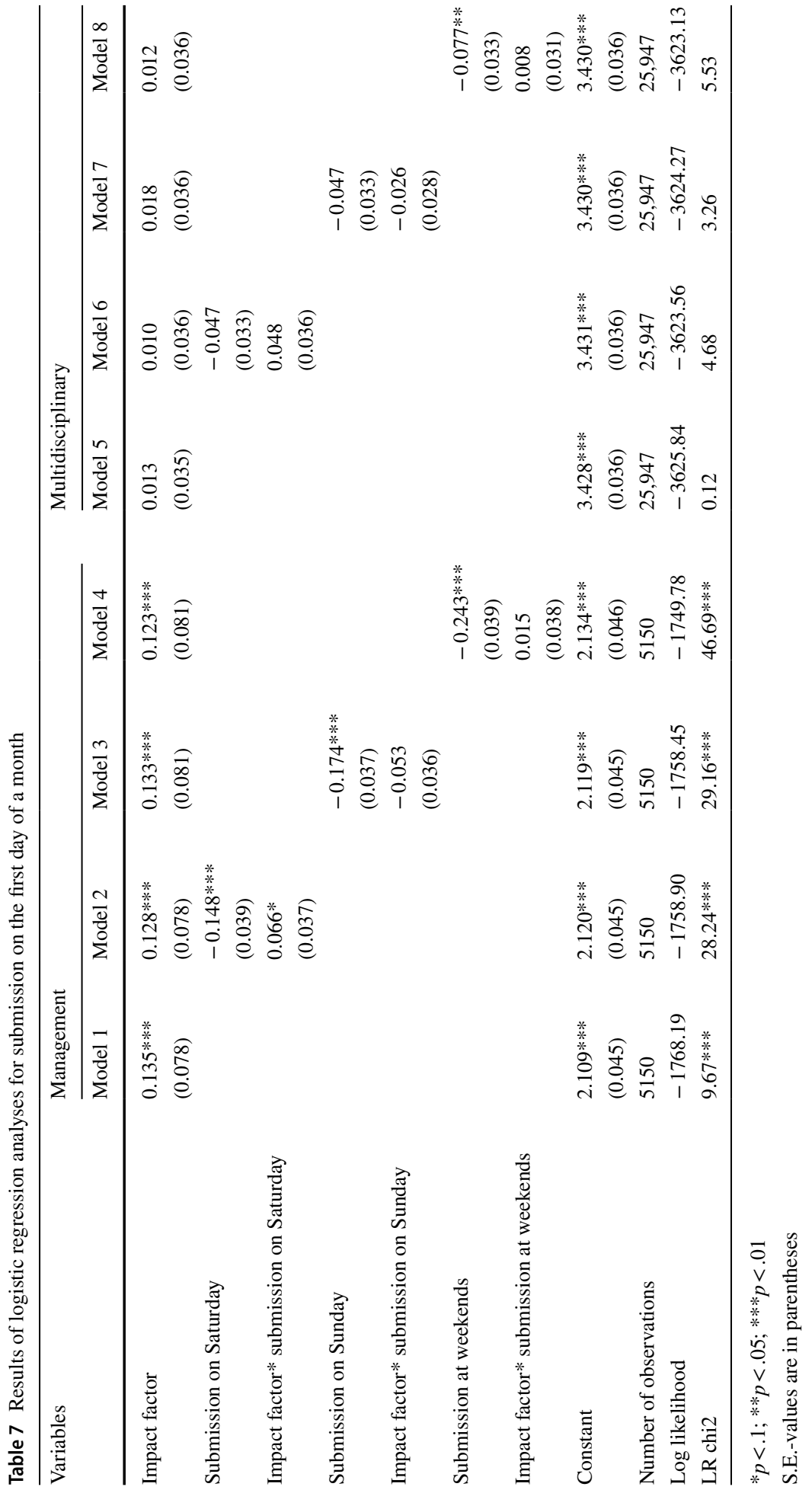




$$
\ln L(w)=\sum_{i=1}^{n}\left[y_{i} \ln \pi\left(x_{i}\right)+\left(1-y_{i}\right) \ln \left(1-\pi\left(x_{i}\right)\right)\right]
$$

where $\pi\left(x_{i}\right)=\frac{1}{1+e^{-g\left(x_{i}\right)}}, \quad g\left(x_{i}\right)=w_{0}+w_{1} x_{i 1}+\cdots+w_{n} x_{i m}, \quad x_{1} \ldots x_{m}$ are independent variables, $y$ is the dependent variable, and $n$ is the sample size. Model 1 to Model 4 examine the ToM effect in submissions to management journals, while Model 5 to Model 8 examine the ToM effect in submissions to multidisciplinary journals. As shown in the results of Model 1 and Model 5, the impact factor of a management journal has a statistically significant positive influence on whether the submission took place on the first day of a month $(b=0.135, p<0.01)$. In other words, the higher the impact factor of a management journal, the more likely that the authors would submit their manuscript on the first day of a month. This result indicates a more pronounced ToM effect in submissions to top-tier management journals. Similar patterns are not found in submissions to multidisciplinary journals $(b=0.013, p>0.1)$.

To further examine the ToM effect at weekends, three moderating variables, submission at weekends, submission on Saturday and submission on Sunday, are included in other logistic regression models, respectively. According to results demonstrated in Model 2 and Model 6, the moderating effect of submission on Saturday is positive and significant in submissions to management journals $(b=0.066, p<0.1)$, which is positive but not significant $(b=0.048, p>0.1)$ in submissions to interdisciplinary ones. According to results shown in Model 3 and Model 7, the moderating effect of submission on Sunday is negative while not significant in both submissions to management journals $(b=-0.053, p>0.1)$ and interdisciplinary ones $(b=-0.026, p>0.1)$. According to results displayed in Model 4 and Model 8, the moderating effect of submission at weekends are positive while not significant in both submissions to management journals $(b=0.015, p>0.1)$ and interdisciplinary ones $(b=0.008, p>0.1)$. These results further suggest that the positive effect of the management journal's impact factor on whether the submission took place on the first day of a month gets more pronounced when the submission date was a Saturday.

Finally, we replace submission on the first day of a month with submission on the last day of a month as the dependent variable, which is also adopted as a dummy variable $(1=$ yes, $0=$ no). It is worth noting that, 31 st is the last day of January, March, May, July, August, October, and December. 30th is the last day of April, June, September, and November, while 28th or 29th is the last day of February depending on whether the given year is a leap year. The results are shown in Table 8. Model 1 to Model 4 examine the effects in submissions to management journals, while Model 5 to Model 8 examine the effects in submissions to multidisciplinary journals. Results suggest that the impact factors of both management and multidisciplinary journals have no significant influence on whether the submission took place on the last day of a month.

\section{Discussion}

In this study, we examine synchronized behaviors of researchers, with a special focus on the day-of-the-month effect in paper submissions. The major finding of this study is that the amount of submissions dramatically increased on the first day of a month. In other words, we observe a turn-of-the-month (ToM) submission effect in accepted papers. It is worth noting that this pattern is only observed in submissions to management journals, but not multidisciplinary journals. The ToM effect is observed on both weekdays 


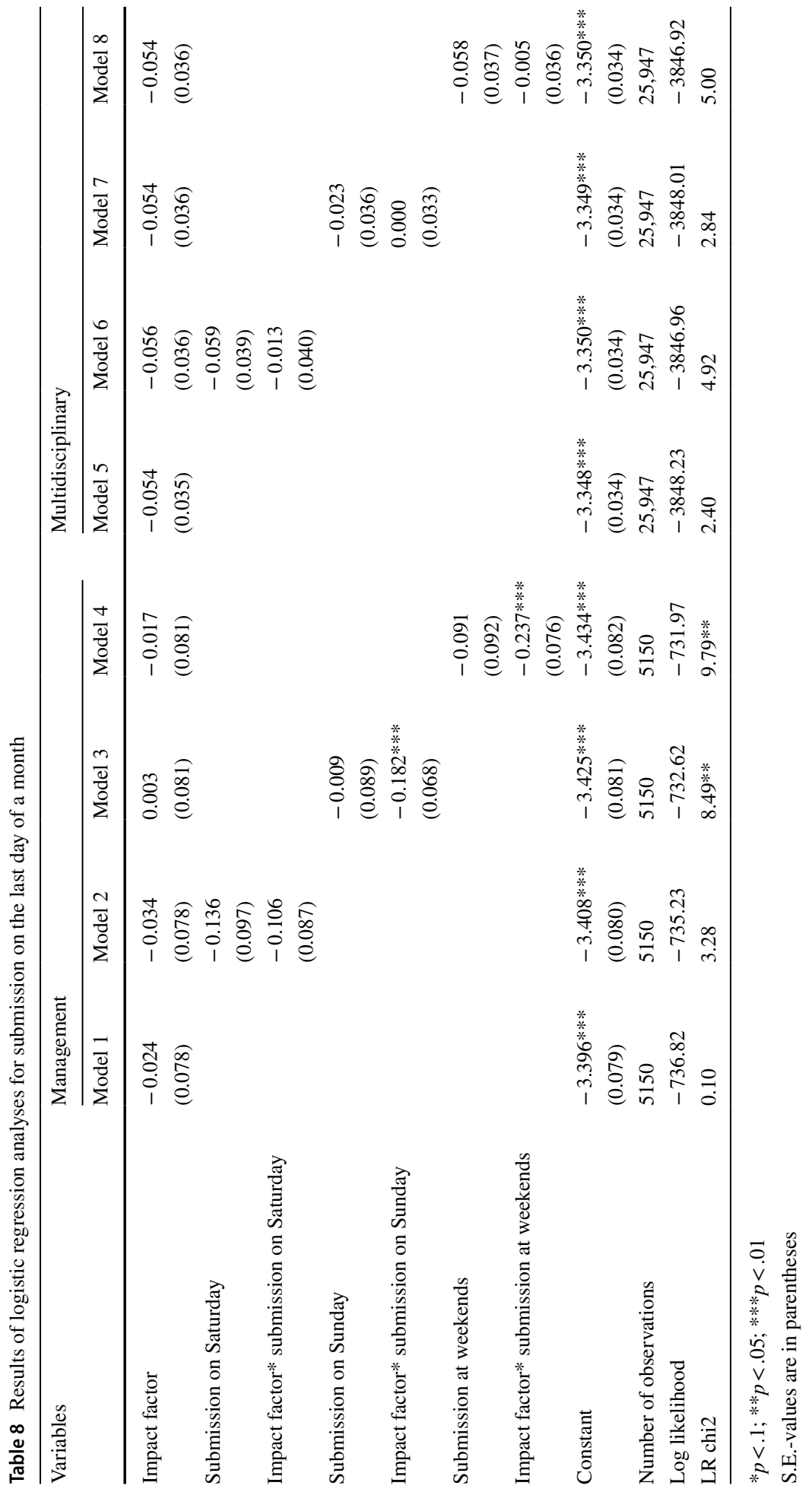


and weekends. The ToM effect is more salient when the manuscript was submitted to a top-tier management journal compared with a middle-grade one. In addition, a stronger effect is observed on weekend submissions, suggesting that the increase in submissions is more pronounced when the first day of a month fell into weekends.

The ToM effect is a widely recognized empirical pattern in the stock market, which is defined as the surge of stock returns during the last day of a month and the first few days of the next month (Kayacetin and Lekpek 2016; Maher and Parikh 2013). It is regarded as a seasonal anomaly and has received widespread research attention. While finance researchers still have not reached a consensus on the causes of this effect, it is widely replicated across the globe (Mclean and Pontiff 2016). Although it is unlikely that the same force is driving it, we observe a similar effect in management academia. As management researchers ourselves, normally we are not in a rush to submit a manuscript as soon as it is ready. It is not uncommon for us management researchers to pick up the submission date we like. It could be a lucky number. It could be an anniversary as well. While we fully understand that actually a carefully chosen submission date would not contribute to the acceptance of the manuscript, this choice just illuminates the way ahead and makes the dull academic life more colorful.

While management researchers may actively pick the submission date, in this study we do not observe obvious clusters in other dates besides the first day of a month. A likely explanation is that meaningful dates are highly personal, which vary for different individuals. If the first day of a month is carefully chosen, then there should be a psychological factor at play. After repeated deliberations, we consider that sense of ceremony might be the driving force. Sense of ceremony is a strong auto-suggestion and a spiritual ritual, which can serve as a powerful motivator (Chappell et al. 2011; Connolly 2010; Huber 2003). While people are guiding their own thoughts, feelings and/or behaviors, a sense of ceremony leads to a placebo effect. For instance, to some of us, taking exercise regularly can be demanding and difficult to persist. However, we may find it less painful if we wear the sports outfits we enjoy very much. This ceremony helps enhance our dedication and psychological well-being. In fact, rituals are of interest to management and psychology researchers and their facilitation role has been recently recognized (Hobson et al. 2018; Tian et al. 2018). For instance, across a series of experiments, a group of leading management scholars found that predefined symbolic actions that lack direct instrumental purpose improve performance in both public and private domains by decreasing one's anxiety (Brooks et al. 2016).

The first day of a month is a representative temporal landmark, which stands out in time and structures one's time perception and usage. Existing management literatures consistently suggested that it has a 'fresh start effect', enhancing people's motivation to pursue their goals right after the landmark (Dai et al. 2014; Dai and Li 2019). Academic life can be tough and sometimes dull. Thus, we speculate that submission of a manuscript on the first day of a month may signify getting a head start for management researchers. To conduct scientific research is never easy. Normally, it would take several years for researchers to complete a study and prepare for manuscript submission. Then, it may take another few years for the submitted manuscript to be accepted and finally published. As one of the most important stages in academic research, the act of submitting a manuscript can be very meaningful to researchers. Through taking this action at the very beginning of a month, management researchers may feel that they have accomplished something fundamental already, and thus are ready to embrace any potential challenges in the upcoming month. Another vision may concern the publication prospect. By doing so, they may also look forward to the successful publication of their work to a greater extent. 
In this study, we find that the ToM effect is stronger when a manuscript is submitted to a top-tier management journal compared with a middle-grade one. It is a common sense that researchers care a lot about the outlet of their research. Thus, when they complete a satisfactory study and decide to try a nice journal, the desire to guarantee its successful publication becomes much stronger. When this is the case, researchers may perceive the sense of ceremony to be more fundamental, which explains why submissions become more concentrated on the first day of a month. Another evidence in support of our speculation is the finding of a stronger ToM effect at weekends. As can be observed in our data, normally submissions show a considerable decline on weekends, which is consistent with findings of previous studies. However, once a Saturday or Sunday happened to be the first day of a month, submissions to management journal accumulated on that day. It is worth noting that, in our dataset a prominent ToM effect is observed on New Year's Day as well, which is a common holiday in most countries. In addition, the amount of accepted papers submitted to management journals on New Year's Day does not significantly differentiate from the amount of accepted papers submitted to management journals on Feb $1^{\text {st }}$, March $1^{\text {st }}$, and so on. Thus, it seems that many management researchers still decide to work and have their manuscripts submitted in common holidays as long as it is the first day of a month. While other researchers considered this act to be a representation of work-life imbalance and blamed the enormous publication pressure in the academia (Barnett et al. 2019; Cabanac and Hartley 2013), we follow the thought of positive psychology and suggest that it may illustrate proactive psychological construction which has positive impacts on the researchers' psychological well-being both in work and life domains. By doing so, management researchers may exhibit stronger subjective initiative and well-being in both domains. It is worth noting that, in our study the ToM effect in manuscript submissions is only observed in management journals, but not multidisciplinary journals. Given that the current evidence is limited, we refrain from giving a very strong explanation. We speculate that management researchers know something about psychology (e.g., temporal landmarks and the 'fresh start effect') and care more about getting along well with themselves.

We would like to acknowledge some limitations of this study. To begin with, as we do not have access to the submission system of any journals, we only analyze public data retrieved from the official websites of selected academic journals. While this allows us to include more journals into our analyses, our analyses are confined to the first submission date of published articles only. On the one hand, it is possible that unpublished articles may exhibit a different monthly submission pattern. On the other hand, if sense of ceremony is indeed the driving force of the ToM effect, then a more pronounced effect might be observed in the submission dates of revisions. Researchers who have access to such data (e.g., Ausloos and Nedic et al. 2019a, b) can test whether this effect holds true for all the manuscripts being submitted as well as in revisions. Secondly, potential sources of measurement error might exist. Authors come from all over the globe. When the submission record suggests that a manuscript was submitted on the first day of a month to a journal published by an Asian publisher, it is likely that it was actually submitted on the last day of a month by a North American submitting author. While we cannot fully eliminate this possibility, we mindfully name our findings the turn-of-themonth effect rather than the beginning-of-the-month effect. Finally, we fully recognize that due to the non-experimental nature of this study, causal relationships cannot be established, and all of the explanations remain our speculations. Still, we consider it to be an interesting phenomenon, which deserves replication and further development. 


\section{Conclusions}

Extending the pioneering studies on day-of-the-week effects in manuscript submissions, we adopt a longer time scale (i.e., the month) and examine the existence of any day-of-themonth effects. To explore effects of reputation of the journal as well as research domain, a large dataset incorporating 10 multidisciplinary journals and 10 management journals is retrieved and analyzed. A strong ToM effect is observed in management journals but not multidisciplinary journals, which gets more pronounced in submissions to top-tier journals and when the first day of a month fell into weekends. Sense of ceremony is adopted as a tentative explanation of the ToM effect, as the act of submitting a manuscript at the very beginning of a month (which is a temporal landmark) may signify the management researchers' wish for successful publication. To conclude, in this study we report a novel unforced regularity in manuscript submissions, which deserves more academic attention.

Acknowledgements This study was supported by Humanities and Social Sciences Research Fund supported by Ministry of Education of China [Grant number: 17YJC630104], the National Natural Science Foundation of China [Grant number: 71701131; 71902116], China Scholarship Council [Grant number: 201806905002], Shanghai Philosophy and Social Science Foundation [Grant number: 2019EGL013], and Foundation of Shanghai International Studies University [Grant number: 2018114053].

\section{Compliance with ethical standards}

Conflict of interest The authors declare that they have no conflict of interest.

\section{References}

Abu Bakar, A., Siganos, A., \& Vagenas-Nanos, E. (2014). Does mood explain the Monday effect? Journal of Forecasting, 33(6), 409-418. https://doi.org/10.1002/for.2305.

Ausloos, M., Nedic, O., \& Dekanski, A. (2016). Day of the week effect in paper submission/acceptance/ rejection to/in/by peer review journals. Physica A: Statistical Mechanics and its Applications, 456, 197-203. https://doi.org/10.1016/j.physa.2016.03.032.

Ausloos, M., Nedic, O., Dekanski, A., Mrowinski, M. J., Fronczak, P., \& Fronczak, A. (2017). Day of the week effect in paper submission/acceptance/rejection to/in/by peer review journals. II. An ARCH econometric-like modeling. Physica A: Statistical Mechanics and its Applications, 468, 462-474. https ://doi.org/10.1016/j.physa.2016.10.078.

Ausloos, M., Nedic, O., \& Dekanski, A. (2019a). Seasonal entropy, diversity and inequality measures of submitted and accepted papers distributions in peer-reviewed journals. Entropy, 21(6), 1-12. https:// doi.org/10.3390/e21060564.

Ausloos, M., Nedič, O., \& Dekanski, A. (2019b). Correlations between submission and acceptance of papers in peer review journals. Scientometrics, 119(1), 279-302. https://doi.org/10.1007/s11192-01903026-X.

Barnett, A., Mewburn, I., \& Schroter, S. (2019). Working 9 to 5, not the way to make an academic living: observational analysis of manuscript and peer review submissions over time. BMJ, 367, 16460. https:// doi.org/10.1136/bmj.16460.

Boja, C. E., Herţeliu, C., Dârdală, M., \& Ileanu, B. V. (2018). Day of the week submission effect for accepted papers in Physica A, PLoS ONE, Nature and Cell. Scientometrics, 117(2), 887-918. https:// doi.org/10.1007/s11192-018-2911-7.

Borowski, M., Busse, D., \& Fried, R. (2015). Robust online-surveillance of trend-coherence in multivariate data streams : the similar trend monitoring (STM) procedure. Statistics and Computing, 25, 913-928. https://doi.org/10.1007/s11222-014-9462-4.

Brooks, A. W., Schroeder, J., Risen, J. L., Gino, F., Galinsky, A. D., Norton, M. I., et al. (2016). Don't stop believing: Rituals improve performance by decreasing anxiety. Organizational Behavior and Human Decision Processes, 137, 71-85. https://doi.org/10.1016/j.obhdp.2016.07.004. 
Cabanac, G., \& Hartley, J. (2013). Issues of work-life balance among JASIST authors and editors. Journal of the American Society for Information Science and Technology, 64(10), 2182-2186. https://doi. org/10.1002/asi.22888.

Campos-Arceiz, A., Koh, L. P., \& Primack, R. B. (2013). Are conservation biologists working too hard? Biological Conservation, 166, 186-190. https://doi.org/10.1016/j.biocon.2013.06.029.

Cellini, R., \& Cuccia, T. (2014). Seasonal processes in the Euro-US Dollar daily exchange rate. Applied Financial Economics, 24(3), 161-174. https://doi.org/10.1080/09603107.2013.870651.

Chappell, D., Chappell, S., \& Margolis, E. (2011). School as ceremony and ritual: How photography illuminates performances of ideological transfer. Qualitative Inquiry, 17(1), 56-73. https://doi. org/10.1177/1077800410389444.

Connolly, T. H. (2010). Business ritual studies corporate: ceremony and sacred space. International Journal of Business Anthropology, 1(2), 32-47. https://doi.org/10.33423/ijba.v1i2.1194.

Dai, H., \& Li, C. (2019). How experiencing and anticipating temporal landmarks influence motivation. Current Opinion in Psychology, 26, 44-48. https://doi.org/10.1016/j.copsyc.2018.04.012.

Dai, H., Milkman, K. L., Riis, J., Dai, H., Milkman, K. L., \& Riis, J. (2014). The fresh start effect: temporal landmarks motivate aspirational behavior. Management Science, 60(10), 2563-2582. https://doi. org/10.1287/mnsc.2014.1901.

Herteliu, C., Ileanu, B. V., Ausloos, M., \& Rotundo, G. (2015). Effect of religious rules on time of conception in Romania from 1905 to 2001. Human Reproduction, 30(9), 2202-2214. https://doi.org/10.1093/ humrep/dev129.

Hobson, N. M., Schroeder, J., Risen, J. L., Xygalatas, D., \& Inzlicht, M. (2018). The psychology of rituals: an integrative review and process-based framework. Personality and Social Psychology Review, 22(3), 260-284. https://doi.org/10.1177/1088868317734944.

Huber, S. J. (2003). The white coat ceremony: a contemporary medical ritual. Journal of Medical Ethics, 29(6), 364-366. https://doi.org/10.1136/jme.29.6.364.

Kayacetin, V., \& Lekpek, S. (2016). Turn-of-the-month effect: new evidence from an emerging stock market. Finance Research Letters, 18, 142-157. https://doi.org/10.1016/j.frl.2016.04.012.

Magnone, E. (2013). A scientometric look at calendar events. Journal of Informetrics, 7(1), 101-108. https ://doi.org/10.1016/j.joi.2012.09.006.

Maher, D., \& Parikh, A. (2013). The turn of the month effect in India: a case of large institutional trading pattern as a source of higher liquidity. International Review of Financial Analysis, 28, 57-69. https:// doi.org/10.1016/j.irfa.2013.02.011.

Mclean, R. D., \& Pontiff, J. (2016). Does academic research destroy stock return predictability? Journal of Finance, 71(1), 5-32. https://doi.org/10.1111/jofi.12365.

Pautasso, M., \& Schäfer, H. (2010). Peer review delay and selectivity in ecology journals. Scientometrics, 84(2), 307-315. https://doi.org/10.1007/s11192-009-0105-z.

Pigman, J.G., Rizenbergs, R.L., \& Herd, D.R. (1978). Analysis of weekday, weekend, and holiday accident frequencies. Research Report No. 513, Division of Research, Bureau of Highways, Department of Transportation, Commonwealth of Kentucky.

Tian, A. D., Schroeder, J., Häubl, G., Risen, J. L., Norton, M. I., \& Gino, F. (2018). Enacting rituals to improve self-control. Journal of Personality and Social Psychology, 114(6), 851-876. https://doi. org/10.1037/pspa0000113.

Zhu, J., \& Liu, W. (2020). A tale of two databases: the use of web of science and scopus in academic papers. Scientometrics, 123, 321-335. https://doi.org/10.1007/s11192-020-03387-8. 